\title{
Pattern of dietary behaviour and obesity in Ahwaz, Islamic Republic of Iran
}

\author{
H. Soori
}

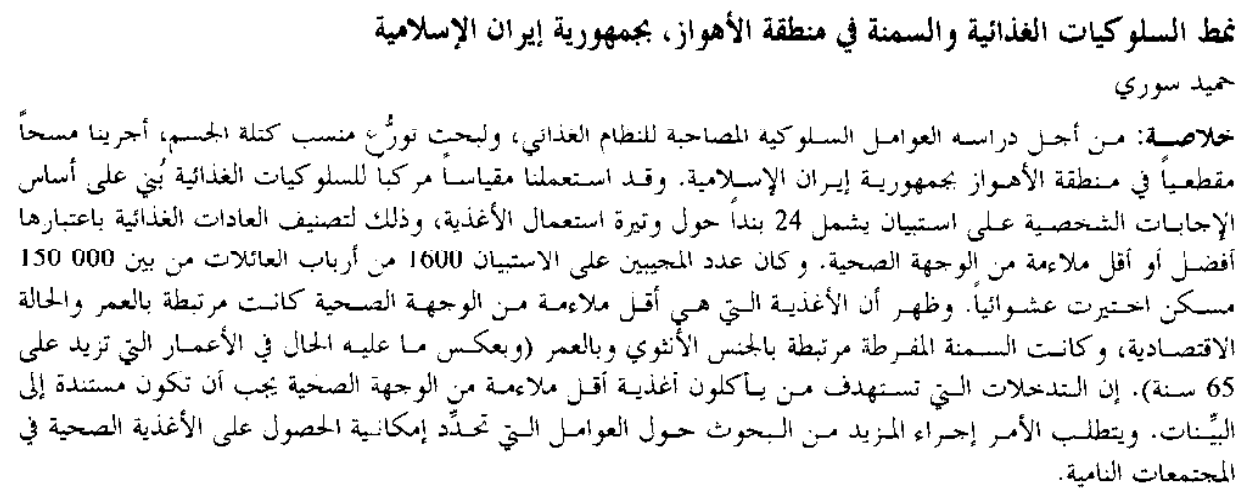

ABSTRACT To study behavioural factors associated with diet and to investigate body mass index distribution, a cross-sectional survey was carried out in Ahwaz. A composite dietary behaviour score obtained from self-reported responses to a 24-item food-frequency questionnaire was used to categorize

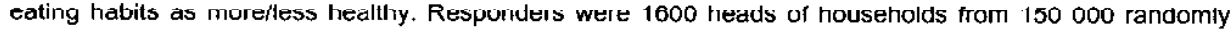
selected residences. Less healthy diets were shown to be associated with age and economic status, and greater obesity with women and age (reversed after ages $>65$ years). Interventions targeted at less healthy eaters need to be evidence-based, and further research into factors determining access to healthy diets in developing communities is required.

Caractéristiques du comportement alimentaire et obésité à Ahwaz (République islamique d'Iran) RESUME Une enquête transversale a été réalisée à Ahwaz afin d'étudier les facteurs comportementaux associés à l'alimentation et d'examiner la distribution de lindice de masse corporelle. Un score composite pour le comportement alimentaire obtenu à partir de réponses à un questionnaire direct sur la fréquence de consommation des atiments comportant 24 produits alimentaires a été utilisé pour classer les habitudes de connsommation comme plus/moins saines. Les personnes interrogées étaient 1600 chefs de famille pris dans 150000 foyers choisis au hasard. II a été montré que les régimes alimentaires les moins sains étaient associés avec l'âge et la situation socio-économique et l'obésité la plus importante avec les femmes et l'âge (inversé après les âges > 65 ans). Les interventions ciblées sur les consommateurs ayant le moins bon étal de santé doivent être fondées sur des données scientifiques probantes el davantaye de recherche est nécessaire sur les facteurs qui déterminent l'accès aux régimes alimentaires sains dans les communautés en developpement.

'Deparment or Community meorcrne, schoos or Mearche, anwaz university or Mearcal scrences, Ahwaz, Islamic Republic of iran.

Received: 30/04/00; accepted: $17 / 09 / 00$

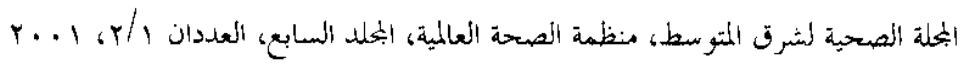




\section{Introduction}

Diet and ohesity are important in the etiology of many diseases, including coronary heart diseases, hypertension, cancers, diabetes, gallstones and orthopaedic impairment $[1,2]$. They have become a focus of attention in health strategies in some countries, with targets for improvement being set in relation to consumption of total and saturated fats $[3,4]$. Recommendations on healthy diets have also been made in relation to consumption of tibre-rich carbohydrates and total energy $[4,5]$. Many factors are associated with dietary behaviour at the family level, such as occupation, wealth and family size [6,7]. At an individual level, diet is associated with appetite, physiological factors and other factors, such as age, body weight, stress and the presence of specific diseases $[7,8]$.

Understanding the complex interaction of different factors is crucial to the development of successful health promotion interventions. In this study, the behavioural factors associated with dietary patterns in the city of Ahwaz, the capital of Khuzestan, in the south-western corner of the Islamic Republic of Iran, are identified. The distribution of categories of body mass index (BMI) is also investigated and variations in dietary behaviour relating to age, sex, economic status and educational attainment are presented.

\section{Methods}

A cross-sectional study, part of a wider lifestyle survey, was carried out to collect data on dietary patterns from heads of households (age range: 18-84 years) living in Ahwaz. A self-reporting questionnaire was administered face-to-face by trained interviewers. The survey was citywide, with 1600 people randomly sampled from 75 wards in Ahwaz, containing in total approximately 150000 native-Iranian households. A random cluster sampling technique was used.

Completed questionnaires were received from 1540 participants, a response rate of $96.3 \%$. The questionnaire included information about the health status of the participants, their diet, leisure-time activities, employment, smoking and use of health services. Questions for the survey were derived from different sources, including the Oxford Healthy Life Survey [9] and Newcastle Health and Lifestyle Survey [10]. The questionnaire was piloted on 100 people and modified accordingly for the Iranian population.

Diet was assessed using a 24-item food-frequency questionnaire. A composite dietary behaviour score was obtained, and respondents were categorized into 2 groups - those scoring above and below the median value of 86 (range: $24-120$ ) indicating less and more healthy eaters re spectively. Participants were asked how often they ate specific foods (e.g. red meat, milk, fish) known to be frequently consumed by Iranian households in their daily diets. All 24 food items were scored on a scale of 1 to 5 according to their healthgiving properties and how often they were eaten, with a higher score indicating a healthier diet. Thus, foods with high fats scored 1 for most days and 5 for rarely or never, whereas foods with high fibre scored 5 for most days and 1 for rarely or never. In computing these scores, it was important to ensure that each participant had a value for each item in order to obtain the composite score. Non-respondents to dietary questions were excluded.

BMI was calculated from the weight and height reported by the participants

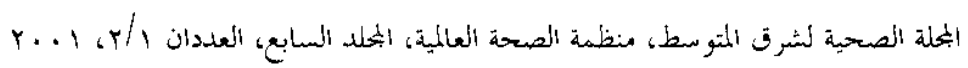


[weight $(\mathrm{kg}) / \mathrm{height}^{2}\left(\mathrm{~m}^{2}\right)$ ]. Using esiablished criteria [II], BMI was categorized into five groups: underweight $\left(<20 \mathrm{~kg} / \mathrm{m}^{2}\right.$ for both sexes), acceptable weight (20-24 $\mathrm{kg} / \mathrm{m}^{2}$ for men; $20-23 \mathrm{~kg} / \mathrm{m}^{2}$ for women), overweight (25-29 kg/m for men; $24-27$ $\mathrm{kg} / \mathrm{m}^{2}$ for women), and obese ( $>30 \mathrm{~kg} / \mathrm{m}^{2}$ for $\mathrm{men}$; $>28 \mathrm{~kg} / \mathrm{m}^{2}$ for women).

Economic status was assessed by reference to car and home ownership. Families with both a car and home counted as less deprived, and without both a car and home, as more deprived. Deprivation status was assessed for 738 participants. Data were analysed using SPSS, version 7.0. The chi-squared test was applied to test for the association between categorized variables. The Mann-Whitney test was used to identify differences between dietary patterns and population groups.

\section{Results}

Table 1 shows the frequency of consumption of the main food items. Many participants consumed foods known to be less healthy several days a week. For example, solid fats, red meat and aerated (fizzy) soft drinks were consumed by a large proportion of respondents, 2 or more days a week. However, a substantial proportion of people also consumed healthier foods (e.g. vegetables, fish, fruits) many days a week.

Table 2 shows the distribution of daily consumption of food groups by deprivation status. Cereals were the most popular food, consumed by $98.6 \%$ of the population daily. Less deprived groups were more likely to consume cereals, vegetables, fruits, meats and milk/diary products $(P<0.005)$. However, there was no significant difference between the consumption of different food groups by age. sex or educational attainment.
Table 3 shows more/less healthy eating behaviours scored above and below the median value by age group, educational attainment and degree of deprivation. Being older and of lower economic status were associated with less healthy diets $(P<$ $0.001)$. However, there was no significant difference between more/less healthy eating hy educational attainment.

Table 4 shows the distribution of BMI by age group, sex and deprivation status. The overall prevalence of obesity was $13.9 \%$ (95\% CI: $11.8-16.1)$. The mean BMI in males was $25.5 \mathrm{~kg} / \mathrm{m}^{2}$ (standard devation $=4.2$ ) and in females $26.9 \mathrm{~kg} / \mathrm{m}^{2}$ (standard deviation $=4.7$ ). There was a significant pattern of greater obesity in females compared to males ( $36.6 \%$ versus $11.9 \%)(P<0.001)$ and in older generations $(P<0.001)$, although this trend appeared to reverse at ages $>65$ years.

\section{Discussion}

This study was the first to be conducted on patterns of dietary behaviour in this society. It shows that many people consume unhealthy foods during their daily food intake, and less healthy diets tend to be consumed in deprived groups and older generations. The results confirm that women and older people tend to be more obese than men and younger people.

As the study was cross-sectional and self-reported, we were unable to draw any conclusions about causation. However, it may be hypothesized that lower cconomic status is importantly related to a less healthy diet in this community. Another limitation of the study that should be considered when interpreting the findings is the validity of the measurements. In addition, the allocation of some food items (e.g. red

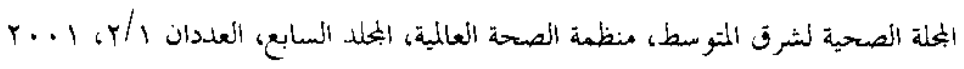




\begin{tabular}{|c|c|c|c|c|c|c|c|c|c|c|}
\hline \multirow[t]{2}{*}{ Food group } & \multicolumn{2}{|c|}{ Most days } & \multicolumn{2}{|c|}{$\begin{array}{l}\text { 2-3 times/ } \\
\text { week }\end{array}$} & \multicolumn{2}{|c|}{ Once/week } & \multicolumn{2}{|c|}{$\begin{array}{l}\text { 1-2 times } \\
\text { month }\end{array}$} & \multicolumn{2}{|c|}{$\begin{array}{c}\text { Rarely or } \\
\text { never }\end{array}$} \\
\hline & No. & $\%$ & No. & $\%$ & No. & $\%$ & No. & $\%$ & No. & $\%$ \\
\hline \multicolumn{11}{|l|}{ Less healthy foods } \\
\hline Solid fat & 1024 & 68.6 & 156 & 10.4 & 81 & 5.4 & 232 & 15.5 & 0 & 0.0 \\
\hline $\begin{array}{l}\text { Red meat } \\
\text { Aerated soft drinks }\end{array}$ & $\begin{array}{l}524 \\
334\end{array}$ & $\begin{array}{l}35.4 \\
22.7\end{array}$ & $\begin{array}{l}644 \\
455\end{array}$ & $\begin{array}{l}43.5 \\
30.5\end{array}$ & $\begin{array}{l}166 \\
280\end{array}$ & $\begin{array}{l}11.2 \\
18.8\end{array}$ & $\begin{array}{l}144 \\
420\end{array}$ & $\begin{array}{r}9.7 \\
28.2\end{array}$ & $\begin{array}{l}2 \\
3\end{array}$ & $\begin{array}{l}0.1 \\
0.2\end{array}$ \\
\hline Cakes/pastries & 334 & 22.7 & 394 & 26.7 & 266 & 18.1 & 477 & 32.4 & 2 & 0.1 \\
\hline Butter & 319 & 21.6 & 311 & 21.1 & 211 & 14.3 & 622 & 14.3 & $\$ 1$ & 0.7 \\
\hline Chooolates & $2 \uparrow 8$ & 14.7 & 341 & 23.1 & 310 & 21.6 & 603 & 40.1 & 7 & 0.5 \\
\hline Ice cream & 189 & 12.9 & 285 & 19.5 & 405 & 27.7 & 577 & 39.5 & 6 & 0.4 \\
\hline Cream & 123 & 22.4 & 178 & 12.2 & 237 & 16.2 & 908 & 62.1 & 15 & 1.0 \\
\hline Sausages & 88 & 6.0 & 221 & 15.1 & 392 & 26.8 & 751 & 51.4 & 9 & 0.6 \\
\hline Processed meat & 87 & 5.9 & 236 & 16.1 & 393 & 26.8 & 739 & 50.4 & 12 & 0.8 \\
\hline \multicolumn{11}{|l|}{ More healthy foods } \\
\hline Bread & 1497 & 98.4 & 17 & 1.1 & 1 & 0.1 & 6 & 0.4 & 0 & 0.0 \\
\hline Tea/coffee & 1474 & 96.7 & 15 & 1.0 & 5 & 0.3 & 0 & 0.0 & 29 & 1.9 \\
\hline Vegetables & 1156 & 76.7 & 213 & 14.1 & 72 & 4.8 & 66 & 4.4 & 1 & 0.1 \\
\hline Fruits & 1097 & 72.9 & 307 & 20.4 & 55 & 3.7 & 46 & 3.1 & 0 & 0.0 \\
\hline Rico & 1072 & 70.8 & 337 & 22.3 & 70 & 4.6 & 35 & 2.3 & 0 & 0.0 \\
\hline Cheese & 1035 & 69.2 & 256 & 17.1 & 72 & 4.8 & 132 & 8.8 & 1 & 0.1 \\
\hline Yoghurt & 1010 & 67.0 & 367 & 24.4 & 75 & 5.0 & 55 & 3.6 & 0 & 0.0 \\
\hline Eggs & 687 & 45.5 & 545 & 36.1 & 112 & 7.4 & 165 & 10.9 & 1 & 0.1 \\
\hline Peas/beans & 657 & 43.5 & 513 & 34.0 & 220 & 14.6 & 120 & 7.9 & 1 & 0.1 \\
\hline Liquid oil & 622 & 42.1 & 142 & 9.6 & 159 & 10.8 & 544 & 36.8 & 12 & 0.8 \\
\hline Chicken & 398 & 26.3 & 756 & 49.9 & 278 & 18.4 & 82 & 5.4 & 0 & 0.0 \\
\hline Milk & 353 & 35.8 & 415 & 27.7 & 220 & 15.1 & 310 & 21.7 & 4 & 0.3 \\
\hline Fish & 272 & 18.0 & 533 & 35.3 & 497 & 32.9 & 204 & 13.5 & 4 & 0.3 \\
\hline Fruit juice & 82 & 5.7 & 110 & 7.6 & 135 & 9.4 & 1096 & 76.0 & 19 & 1.3 \\
\hline
\end{tabular}

\begin{tabular}{|c|c|c|c|c|c|c|c|}
\hline \multirow[t]{2}{*}{ Food group } & \multicolumn{2}{|c|}{ More deprived } & \multicolumn{2}{|c|}{ Less deprived } & \multicolumn{2}{|c|}{ Total } & \multirow[t]{2}{*}{$P$-value } \\
\hline & No. & $\%$ & No. & $\%$ & No. & $\%$ & \\
\hline Cereals & 404 & 97.0 & 324 & 100.0 & 720 & 98.6 & 0.013 \\
\hline Vegetables & 302 & 69.4 & 274 & 82.8 & 576 & 75.2 & $<0.001$ \\
\hline Fruits & 294 & 68.1 & 281 & 85.7 & 575 & 75.7 & $<0.001$ \\
\hline Meats & 318 & 79.5 & 271 & 87.7 & 589 & 83.1 & 0.004 \\
\hline Milk/diary products & 331 & 83.2 & 299 & 94.6 & 630 & 88.2 & 0.004 \\
\hline Total $\left.\right|^{a}$ & 414 & & 324 & & 738 & & \\
\hline
\end{tabular}

The total figures less than the sum of observations $(738)$ are missing responses. 


\begin{tabular}{|c|c|c|c|c|c|}
\hline \multirow{3}{*}{$\begin{array}{l}\text { Variable } \\
\text { Age group (years) }\end{array}$} & \multirow{2}{*}{\multicolumn{2}{|c|}{$\begin{array}{l}\text { More healthy eaters } \\
\text { No. } \quad \%\end{array}$}} & \multicolumn{2}{|c|}{ Less healthy eaters } & \multirow{2}{*}{ P-value } \\
\hline & & & No. & $\%$ & \\
\hline & & & & & $<0.001$ \\
\hline$\leq 24$ & 12 & 63.2 & 7 & 26.8 & \\
\hline $25-34$ & 167 & 66.5 & 84 & 33.5 & \\
\hline $35-44$ & 239 & 55.3 & 103 & 44.7 & \\
\hline $45-54$ & 137 & 44.6 & 170 & 55.4 & \\
\hline 55.64 & 54 & 37.0 & 92 & 63.0 & \\
\hline$\geq 65$ & 29 & 31.2 & 64 & 68.8 & \\
\hline Deprivation status & & & & & $<0.001$ \\
\hline More deprived & 133 & 38.2 & 215 & 61.8 & \\
\hline Less deprived & 145 & 52.5 & 131 & 47.5 & \\
\hline Educational attainment & & & & & NS \\
\hline Uneducated & $8 t$ & 45.8 & 96 & 54.2 & \\
\hline Primary school & 170 & 49.7 & $\$ 72$ & 50.3 & \\
\hline Middle school & 100 & 55.4 & 87 & 44.0 & \\
\hline High school & 183 & 52.3 & 167 & 47.7 & \\
\hline University & 106 & 53.3 & 93 & 46.7 & \\
\hline
\end{tabular}

NS $=$ not significant at $5 \%$ level.

\begin{tabular}{|c|c|c|c|c|c|c|c|c|c|}
\hline \multirow[t]{2}{*}{ Variable } & \multicolumn{2}{|c|}{ Underweight } & \multirow{2}{*}{\multicolumn{2}{|c|}{$\begin{array}{l}\text { Acceptable weight } \\
\text { No. } \%\end{array}$}} & \multicolumn{2}{|c|}{ Overweight } & \multicolumn{2}{|c|}{ Obese } & \multirow{2}{*}{$\begin{array}{l}\text { Total } \\
\text { No. }\end{array}$} \\
\hline & No. & $\%$ & & & & $\%$ & No. & $\%$ & \\
\hline \multicolumn{10}{|c|}{ Age group (years) } \\
\hline$\leq 24$ & 5 & 38.4 & 4 & 30.8 & 3 & 23.1 & 1 & 7.7 & 13 \\
\hline $25-34$ & 30 & 13.4 & 90 & 40.2 & 81 & 36.2 & 23 & 10.3 & 224 \\
\hline $35-44$ & 22 & 6.1 & 127 & 35.0 & 158 & 43.5 & 56 & 15.4 & 363 \\
\hline $45-54$ & 13 & 5.5 & 103 & 43.6 & 85 & 36.1 & 35 & 14.8 & 236 \\
\hline $55-64$ & 4 & 4.6 & 40 & 47.1 & 27 & 31.8 & 14 & 16.5 & 85 \\
\hline$\geq 65$ & 5 & 8.6 & 27 & 46.6 & 18 & 31.0 & 8 & 13.8 & 58 \\
\hline \multicolumn{10}{|l|}{ Deprivation status } \\
\hline More deprived & 26 & 9.1 & 115 & 40.2 & 111 & 38.8 & 34 & 11.9 & 286 \\
\hline Less deprived & 16 & 7.0 & 80 & 34.9 & 104 & 45.4 & 29 & 12.7 & 229 \\
\hline \multicolumn{10}{|l|}{ Sex } \\
\hline Male & 73 & 8.1 & 374 & 41.6 & 345 & 38.4 & 107 & 11.9 & 899 \\
\hline Female & 6 & 7.3 & 18 & 22.0 & 28 & 34.1 & 30 & 36.6 & 82 \\
\hline Total & 79 & 8.0 & 396 & 39.9 & 379 & 38.2 & 138 & 13.9 & 992 \\
\hline
\end{tabular}

ap < 0.001 (analycos standardizod for age and sox).

Total figures less than the sum of observations are missing responses.

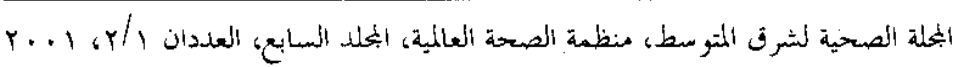


meat, coffee) in less or more healthy diets is open to question.

The findings of the study concur with the findings of others. Anderson and Hunts [6] and White et al. [10] explored eating patterns of populations in Glasgow (Scotland) and Newcastle-upon-Tyne (England) using similar methods. With similar findings. they concluded that nutritional health promotion interventions should be targeted more at lower-income groups. Nutritional health promotion has traditionally been presented in hospitals or community settings, aimed at individuals with identified nutritional problems $[10,12]$. However, newer approaches aimed at achieving a healthy diet within households, and other specifically targeted interventions, are based on epidemiological patterns of nutrition in the population [/3]. Such approaches are designed to counter socioeconomic barriers and to focus on the more deprived meribers of the community.

There have been great changes in the dietary habits of Middle Eastcrn populations in the past decades [2]. A wide range of epidemiological studies has implicated obesity as a significant predisposing risk factor in a variety of disabling and life-threatening medical conditions [/2]. The higher prevalence of obesity in this study compared to other studies $[14,15]$ points to the need for more effective interventions to decrease the problem in this community.

Obesity has been reported to affect $15 \%$ of men and $16.5 \%$ of women in the United Kingdom [5]. Some studies have shown that rates of obesity are higher in industrialized than developing countries [15]. However, there are some notable exceptions, such as in parts of India [16], and as shown in the present study. The prevalence of obesity (BMI $\geq 30 \mathrm{~kg} / \mathrm{m}^{2}$ for both sexes) for 19-70-year-olds in Isfahan,
Islamic Republic of Iran has been reported at $27.0 \%$ for women and $24.8 \%$ for men [17]. A study to determine the prevalence of obesity in Saudi Arabia found $28 \%$ of Saudi males in the Riyadh region were obese (BMI $\left.>30 \mathrm{~kg} / \mathrm{m}^{2}\right)$ [18].

The rising prevalence of obesity in developing countries is now a major public health issue. Population-based prevention strategies aimed at effecting a downward shift in BMJ distribution seem to be the most appropriate strategy for tackling the problem [19]. In countries that have undergone or are undergoing economic transition, obesity is mote likely to be linked to cohorts of lower, rather than higher socioeconomic status. The reasons for this are multifactorial and not well documented. They may be due to, among other things, the long-term trend for the price of food relative to other goods and services to decline (thereby increasing the attordability and accessibility of foodstuffs as incomes rise); over-eating as a compensatory response to a perceived lack of fulfilment in other areas of life: the impulse of undernourished populations to seek out high-fat foods; the reduced opportunity for cxercise in increasingly sedentary modem lifestyles; and the habitual tendency to eat in order to alleviate stress.

Obesity has previously been significantly associated with age [20]. This association was clearly seen in this study. With regard to sex, significant differences in both BMI and obesity prevalence were found. Previous studies have also confirmed a higher prevalence of obesity among women than men $[14,21,22]$. It appears to be mainly due to the lower physical activity levels of women, which are generally culturally endorsed in our community.

In conclusion, education policy and economic interventions to promote healthi-

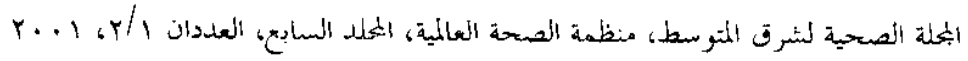


er eating and to encourage exercise should be targeted at the poor, the less well educated, the older generations and women. The relationships between the availability and price of food and its consumption in a healthy diet need to be explored further, using different methods and appropriate inter. vention studies. Such interventions should be based on a thorough assessment of need, and should undergo precise evaluation to determine their effectiveness and efriciency. Further research is needed to explore the factors that determine access to a healthy diet.

\section{Acknowledgements}

This study was supported by a grant from Ahwaz University of Medical Sciences, Islamic Republic of Iran. The author would like to thank Dr F. Ershad and Dr. NikKhooy for their assistance.

\section{References}

1. Diet, nutrition, and the provention of chronic diseases. Report of a WHO study group. Geneva, World Health Organization, 1990 (WHO Technical Report Series, No. 797).

2. Shetty PS, McPherson K, eds. Diet, nutrition and chronic disease: lessons from contrasting worlds. Chichester, Wiley, 1997.

3. The Scottish Office. Scotland's health a challenge to us all ..- executive summary of the Scottish diet. Edinburgh, The Scottish Office, Home and Health Department, 1993.

4. Department of Health. Eaf well. An action plan from the Nutrition Task Force fo achieve the nealth of the nation targets on diet and nutrition. London, Her Majesty's Stationery Office, 1994.

5. Prescott-Clarke P, Primatesta $P$, eds. Health survey for England 1995. London, Her Majesty's Stationery Office, 1907.

6. Anderson AS, Hunt K. Who are the healthy eaters? Eating patterns and health promotion in the west of Scotland. Health education journal, 1992, 51:3-10.
7. Dobeon $\mathrm{B}$ ot al. Diot, ohoico ond povorty: social, cultural and nutritional aspects of food consumption among low-income families. London, Family Policy Studies Centre, 1995.

8. Abel T, McQueen D. Determinants of selected unhealthy eating behaviours among male and female adults. European journal of public health, 1994 , 4:27-32.

9. University of Oxford, Department of Public Health. Oxford Healthy Life Survey. Oxford, Oxford Regional Health Authortty, 1997.

10. White $M$ et al. The Newcastle Health and Lifestyle Survey 1991: user manual. Newcastle-upon-Tyne, Newcastle Health Authority and University of Newcastle, 1993.

11. National Advisory Committee on Nutrition Education. Proposals for nutritional guidelines for health education in Britair. London, Health Education Council, 1983.

12. Sjöström L, Närbro K, Sjöström D. Costs and benefits when treating obesily- International journal of obesity and related

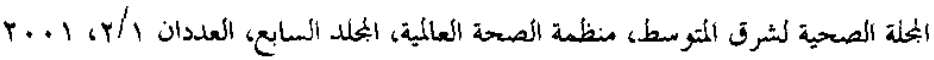


metabolic disorders: journal of the International Association for the Study of Obesity, 1995, 19(suppl. 6):S9-12.

13. Roe $L$ et al. A systematic review of the effectiveness of interventions to promote tiedthy eating. London, Health Education Authority, 1999.

14. Bagust $A$ et al. The additional cost of obcsity to the health scrvice and the po tential for resource saving from effective interventions. European journal of public health, 1999, 9:258-64

15. Dyer R. The changing shape of obesity: Japan 1990. Diabetic medicine: a journal of the British Diabetic Association, 1990, 8:492-4.

16. Dhurandhar NV, Kulkarni PR. Prevalence of obesity in Bombay. International journai of obesity and related metabollc disorders: joumal of the International Association for the Study of Obesity, 1992, 16:367-75

17. Sarraf-Zadegan N, Boshtam M, Rafiei M. Risk factors for coronary artery disease in Isfahan. Iran. European journal of public health, 1999, 9:20-6.
18. Al-Shammari SA, Khoja TA, Al-Maatouq MA. The prevalence of obesity among Saudi males in Riyadh region. Annals of Saudi medicine, 1996, 16:269-73.

19. James W. A public health approach to the problem of obesity. International joumal of obesity and related metabolic disorders: journal of the International Assoclation for the Study of Obesity, 1995, 19 (suppl. 3):\$37-45.

20. Moens $G$ et al. Body mass index and health among the working population. Epidemiological data from Belgium. European journal of public health, 1999. 9:119-23.

21. Stamler J. Epidemic obesity in the United States. Archives of internal medicine, $1993,153: 1040-4$.

22. Scottish Intercollegiate Guidelines Network (SIGN). Obesify in Cortland: integrating prevention with weight measurement. Edinburgh, Scottish Intercollegiate Guidelines Network, 1996.

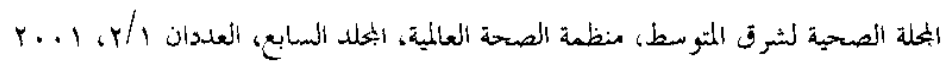

